\title{
An economic model of the long-term health care burden of Type II diabetes
}

\author{
A. Bagust ${ }^{1}$, P.K.Hopkinson ${ }^{2}$, W.Maier ${ }^{3}$, C.J.Currie ${ }^{4}$ \\ ${ }^{1}$ York Health Economics Consortium, University of York, York, UK \\ ${ }^{2}$ Health Outcomes, Glaxo Wellcome Research, Greenford, Middlesex, UK \\ ${ }^{3}$ World Wide Epidemiology, Glaxo Wellcome Research, Research Triangle Park, North Carolina, USA \\ ${ }^{4}$ Department of Medicine, University Hospital of Wales, Cardiff, Wales, UK
}

\begin{abstract}
Aims/hypothesis. To develop a long-term economic model of health care for Type II diabetes initially for the United Kingdom; characterize experiences of diabetes-related morbidities and the use of health care resources among a typical Type II diabetes cohort; to estimate lifetime differences in expected health outcomes and costs attributable to Type II diabetes; and to facilitate evaluation of policies or interventions in treating Type II diabetes from the funder's perspective.

Methods. A compact spreadsheet structure of interconnected Markov chain modules was developed to facilitate rapid estimation of costs and outcomes for whole populations. Recent clinical findings from the United Kingdom Prospective Diabetes Study and other sources were incorporated and a detailed costing module developed from United Kingdom observational data.
\end{abstract}

Results. The model allows the assessment of costs and long-term complications experienced by people suffering from Type II diabetes, including direct health care costs associated with the main diabetic complications and second-order effects on other health services required by such patients. Initial results suggest that the lifetime cost of health care for patients from the diagnosis of diabetes is more than double that for an equivalent non-diabetic population.

Conclusion/interpretation. The model is intended for use by health care policy makers and payers to assess the long-term budgetary impact of trends in a variety of demographic and epidemiological factors on future services, and is also useful to physicians when considering the impact of new treatment strategies or programmes to modify risk factors for diabetic complications. [Diabetologia (2001) 44: 2140-2155]

Keywords Type II diabetes, economic model, epidemiology, health care costs.
Type II (non-insulin-dependent) diabetes mellitus is a common chronic illness with a prevalence as high as $8 \%$ in many countries [1]. In Europe approximate-

Received: 19 March 2001 and in revised form: 6 August 2001

Corresponding author: A. Bagust, York Health Economics Consortium, University of York, Heslington, York, YO10 5DD, UK, e-mail: ab13@york.ac.uk

Abbreviations: CHD, Coronary heart disease; CVD, cardiovascular disease; DCCT, Diabetes Control and Complications Trial; ESRD, end-stage renal disease; GPMDP, General Practice Morbidity Database Project; GPR, gross proteinuria; MA, microalbuminuria; NIH, National Institutes of Health; PDR, proliferative diabetic retinopathy; PVD, peripheral vascular disease; SBP, systolic blood pressure ly 27 million people suffer from diabetes, $80-90 \%$ of whom have Type II diabetes [2]. Due to increased life expectancy, increased frequency of diagnosis and lifestyle changes, the prevalence of this disease in $\mathrm{Eu}-$ rope is expected to increase by $50 \%$ over the next 15 years. Approximately $50 \%$ of people with Type II diabetes are thought to be undiagnosed [3] because its onset is gradual and could precede diagnosis by up to 7 years [4].

Diabetes imposes a substantial burden on both individuals [5] and health-care budgets. In the UK, annual diabetes costs were estimated at $£ 547$ million in 1995 , with $64 \%$ of these costs resulting from hospital in-patient care [6]. This large hospital care burden is a result of the treatment of retinal, renal, neuropath- 
ic, cerebrovascular and cardiac complications that occur with increasing frequency and severity as the disease progresses. Observational studies have indicated that over a 10-year period, substantial proportions of people with Type II diabetes could develop either end-stage renal disease (11\%) [7], macular oedema (14-25\%) [8], lower-extremity amputation (7.3\%) [8], or acute myocardial infarction (30\%) [9].

Hyperglycaemia appears to be the primary cause in the development of renal, retinal and neuropathic complications. Observational studies [8] have shown a 1.1- to 1.8-fold increase in the risk of these complications with every $1 \%$ increase in the serum level of $\mathrm{HbA}_{1 \mathrm{c}}$. In Type I (insulin-dependent) diabetes mellitus, the Diabetes Control and Complications Trial (DCCT) [10] demonstrated that treatment to normalise serum glucose produced substantial reductions in the incidence of retinopathy, nephropathy and neuropathy. Intensive efforts to maintain glycaemic control have also been shown to reduce the incidence of these complications among people with Type II diabetes [11]. The cause of cardiovascular disease (CVD) in Type II diabetes is, however, less clear. Although hyperglycaemia is associated with an increased risk of CVD [12-14], debate has centred around whether hyperglycaemia is directly implicated or whether it is only a marker of the effect of insulin resistance $[15,16]$, the underlying cause of Type II diabetes [17-20].

Diabetes presents a range of challenges to health care policymakers who have to determine future demand for services, assess the potential of new technology to improve outcomes, and estimate the benefits and costs likely to flow from implementing prevention programmes and treatment guidelines. These challenges are compounded by the accumulation of uncertainties involved in projecting the course of patients' future health status and use of health services across several decades. These include secular trends in disease incidence and risk factor prevalence in the population, the impact of changes in the age distribution of the population on demand for services and costs, and imprecise estimates of the rates of progression of the complications of diabetes, and the factors which influence them.

Because policymakers are required to make decisions and to allocate resources which are likely to have important and lasting consequences for many thousands of people, the analytical framework offered by epidemiological and economic modelling is a necessity. However, achieving an acceptable degree of reliability in the estimation of outcomes and costs which could be expected over the life-time of patients requires considerable sophistication in modelling techniques and access to appropriate and detailed data sources. Short-term models are often quite forgiving of imprecise structural or parametric assumptions but a lifetime model accumulates and amplifies errors leading to potentially large discrepancies in outcomes. Previous models have been particularly weak in their treatment of costs, relying either on crude single figure estimates for lifetime care of a condition, or on theoretically constructed 'bottomup' costing. These shortcomings suggest that there is further scope for improving the epidemiological structure of such models and employing large-scale observational data in cost estimation, to offer health care decisionmakers at all levels a better account of the impact of long-term diabetic complications.

The economic model described here was developed with three main objectives: to characterize the lifetime experience of diabetes-related morbidities and use of health care resources among a typical population of patients diagnosed with Type II diabetes; to estimate the difference in expected health outcomes and health costs attributable to Type II diabetes over a lifetime; and to provide a basis for evaluation of future policies or interventions in the treatment of Type II diabetes from the perspective of a funder of health services (initially the UK National Health Service). This paper describes the methods and assumptions of the model, and demonstrates its capabilities by means of some illustrative results.

\section{Subjects and methods}

Epidemiology. The major long-term complications of Type II diabetes were first modelled in a U.S. context [21,22]. Studies estimated the lifetime benefit from more rigorous treatment of hyperglycaemia, adapting methods previously employed for Type I diabetes based on the Diabetes Control and Complications Trial (DCCT) [10]. A discrete event simulation formulation (the National Institutes of Health (NIH) model) was used to estimate the effect of a range of factors, subject to random variations (Monte Carlo randomisation), on a cohort of people with Type II diabetes, yielding estimates of the morbidity experienced by the cohort from diagnosis of diabetes until death. Although alternative approaches to modelling have been developed [23], most authors have followed a variant of the NIH approach [24], incorporating modifications to reflect later evidence, especially from UKPDS $[25,26]$.

The model described here differs in both perspective and modelling technique from most previous models in order to allow exploration of therapeutic and policy alternatives as they impact on people with Type II diabetes in a typical general population. The logical framework governing the progression of diabetes and its complications takes account of recent findings and corrects several anomalies. We chose to replace Monte Carlo simulation with a network of classical interconnected Markov chain modules. This has several benefits: it allows a whole cohort to be represented simultaneously without the extended response times of Monte Carlo models; there is no need to postulate specific probability distributions for each of the model's parameters or to hypothesize covariance relationships; and the progression of patient groups between states is transparent to users. The model was constructed as a Microsoft Excel spreadsheet, and will fully recalculate all estimates in $3-15$ s on a Pentium II 233Mhz PC with $160 \mathrm{Mb}$ RAM and about s on a Pentium III $800 \mathrm{MHz}$ PC with $256 \mathrm{Mb}$ RAM. 


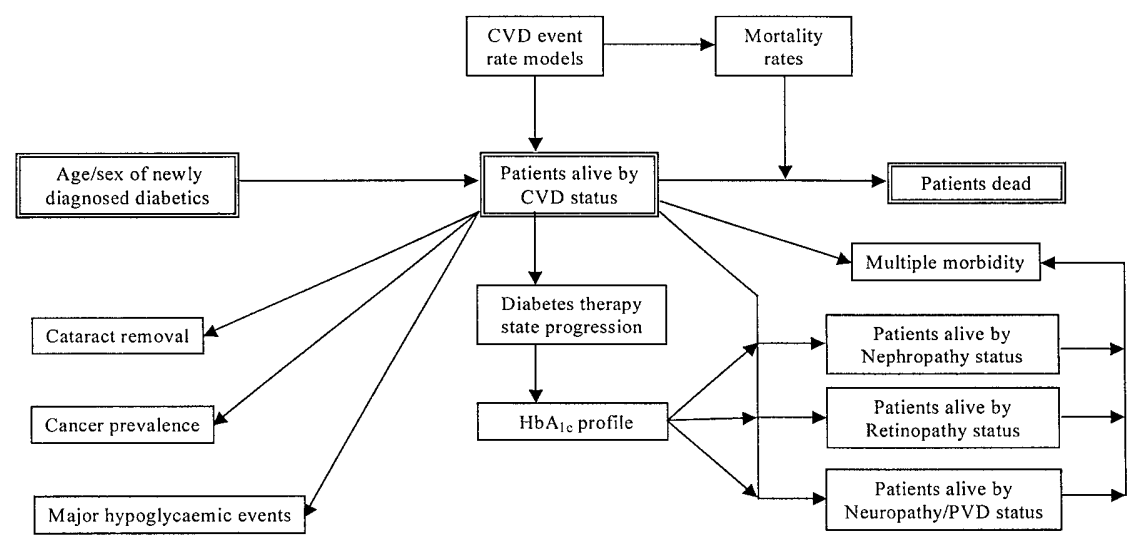

Fig. 1. Model structure showing interrelations between modules

The main limitation imposed by this approach is loss of information concerning the distribution of some patient outcomes for individual patients about the central estimate. However, it is questionable whether Monte Carlo models can provide reliable distributional information (most underlying probability distributions and parameters being assumed on the basis of minimal empirical data). Indeed, we are not aware of any case where outcome confidence limits have been published for such models of diabetic complications. Instead we prefer to perform conventional sensitivity analyses to indicate the degree of uncertainty associated with each value or functional form assumed in the model.

Patients are generated within the model at any age over 20 years, and have their condition and life history updated regularly until death, according to a variety of transition and event rates. These rates can be varied by duration of diagnosed Type II diabetes, age, gender, and ethnicity. To avoid producing an unmanageably large structure, the model was designed in 5year age and diagnosis bands, using algebraic formulations to preserve the accuracy of annual transitions (Appendix 1 shows the relationships derived for the nephropathy module; similar formulae apply to other modules). In effect, 30 parallel models are calculated simultaneously (15 age bands for each gender). This provides immediate estimates of the prevalence of all morbid states for any mixed age and sex cohort of newly diagnosed patients.

Module structure. The modular structure of the model is illustrated in Figure 1. The longevity of patients is governed by a central survival module linked to a set of cardiovascular risk factor sub-models which act to modify normal annual mortality rates for the additional mortality risks affecting people with diabetes, and also directly on surviving patients to determine their current cardiovascular disease status.

Patients are assigned to one of four broad classes of diabetic therapy: diet only, first-line oral medication, second-line (usually combination) therapy, and insulin-based therapy. A sub-model estimates the net progression over time between states from good to increasingly poor glycaemic control. This allows calculation of $\mathrm{HbA}_{1 \mathrm{c}}$ estimates, which are used to modify transition rates in the microvascular complication modules.

The three principal microvascular long-term complications of diabetes (nephropathy, neuropathy and retinopathy) are each represented by a separate independent module. To ensure consistency the model incorporates reconciliation algo- rithms at each period end, to match numbers of patients alive in all modules to the central survival total. The prevalence of multiple severe diabetic complications (including coronary heart disease (CHD) and stroke) is estimated by the application of conditional probabilities reported for South Glamorgan [27].

Cardiovascular disease and mortality module. In common with previous work, and in the absence of more recent comparable results we have incorporated the Framingham multi-variate risk models for cardiovascular morbidity and mortality, pending availability of more recent risk estimation algorithms from UKPDS or other sources. Eastman and co-workers applied a scaling factor (set to 2.75) to the non-CVD mortality rates of the non-diabetic population to estimate elevated mortality from non-CVD causes among people with diabetes. This was introduced to achieve consistency with a reported reduction in life expectancy of 5 to 10 years for middle-aged people with diabetes compared with matched people without diabetes [28]. However, studies in the UK [9] and the US [29] describing the cause of death of people with diabetes, suggest that nonCVD mortality rates are no greater, and could even be less than those for people without diabetes. This is consistent with UK/US evidence that although Type II diabetes increases the risk of all-cause mortality by about twofold, the majority of this excess risk is attributable to the increased risk of death from ischaemic heart disease, diabetes and cerebrovascular causes [28]. Diabetes could also be associated with a slightly greater mortality risk from pneumonia and influenza among older people [28]. However, Type II diabetes does not appear to affect the risks of death from cancer and other diseases [28]. Epidemiological evidence also indicates that the risk of mortality attributable to diabetes declines with age [28]. On this basis we judged that there were no secure grounds for inflating the risk of non-CVD and non-diabetic mortality among patients with Type II diabetes. Using a competing risks formulation we predicted a small reduction in deaths from non-CVD causes, due to the pre-empting effect of CVD mortality in patients with Type II diabetes. However, it is important to recognise that mortality rates are not uncorrelated with the severity of complications; death rates increase steadily with advancing nephropathy in Type I diabetes [30], an effect which is mirrored in Type II diabetes [31]. Therefore, differential mortality risks are estimated in our model for each complication module separately as part of the model calibration process.

An important factor in the progression of cardiovascular disease is the relatively high rate of pre-existing heart disease and history of stroke in both diabetic and non-diabetic populations. This distinguishes the experience of subjects enrolled in most clinical trials (which usually exclude patients with evidence of pre-existing disease) from estimates of morbidity for 
Table 1. Nine distinct morbid states in the retinopathy module

\begin{tabular}{ll}
\hline State code & State description \\
\hline E1 & $\begin{array}{l}\text { No retinopathy } \\
\text { E2 }\end{array}$ \\
E3/B1 & $\begin{array}{l}\text { Mackground diabetic retinopathy } \\
\text { E3/B2 }\end{array}$ \\
E4/B1 & Macular oedema with blindness in one eye \\
E4/B2 & $\begin{array}{l}\text { Proliferative diabetic retinopathy with blindness } \\
\text { in one eye }\end{array}$ \\
E5/B1 & $\begin{array}{l}\text { Macular oedema and proliferative diabetic } \\
\text { retinopathy }\end{array}$ \\
E5/B2 & $\begin{array}{l}\text { Macular oedema and proliferative diabetic } \\
\text { retinopathy with blindness in one eye }\end{array}$ \\
B3 & Blindness in both eyes \\
\hline
\end{tabular}

the general population. The central mortality module of our model estimates the prevalence of all cardiovascular disease, coronary heart disease and history of stroke among survivors at all ages.

Findings from the UKPDS show the effects on mortality and other outcomes of tight control of hypertension and hyperglycaemia $[25,26]$. In particular a long-term reduction in systolic blood pressure (SBP) of $10 \mathrm{mmHg}$ was associated with a $29 \%$ reduction in cardiovascular mortality (median follow-up 8.4 years), and $9 \mathrm{mmoll}^{-1}$ reduction in fasting plasma glucose was linked to $7 \%$ fewer cardiovascular deaths (median 10 years follow-up). Although UKPDS was underpowered to detect changes in mortality of less than $20 \%$, [32] the pattern of responses reported for glycaemic control is suggestive of effects of sufficient magnitude to be important for long-term modelling. We have therefore adopted a conservative estimate for mortality reduction, and have done sensitivity analysis on this assumption. In the absence of a comprehensive replacement for the Framingham models, these effects were introduced as independent risk adjustments to the estimates of cardiovascular deaths in the model, to reflect the anticipated benefits in extended life of improved therapeutic control.

Micro-vascular modules. The nephropathy module follows Eastman's formulation [21] with four nephropathic states: no nephropathy, microalbuminuria (MA), gross proteinuria (GPR) and end-stage renal disease (ESRD).

The neuropathy module was redesigned to incorporate peripheral vascular disease (PVD) as well as neuropathy in accordance with the pathogenesis of foot ulceration and amputation defined by Boulton [33]. The structure comprises seven distinct morbid states: no neuropathy, symptomatic neuropathy, PVD, neuropathy and PVD, diabetic foot ulceration, and first and subsequent lower extremity amputations.

The reformulation of the retinopathy module involved the identification of nine distinct morbid states (Table 1). From five elemental transitional probabilities, a total of 18 compound transition rates were calculated, each of which increases with the duration of diagnosed diabetes.

$H b A_{1 c}$ module. UKPDS findings [25] show clearly that $\mathrm{HbA}_{1 \mathrm{c}}$ concentrations rise steadily in a non-linear fashion regardless of the therapeutic regimen. To reflect this observation, the model includes a module to estimate the change over time of average glycaemic levels using four therapy stages (diet and exercise only, first and second-line oral hypoglycaemic agents, and insulin-based therapy), and incorporates a therapeutic target for $\mathrm{HbA}_{1 \mathrm{c}}$ which can be varied from conventional to intensive glycaemic control in accordance with UKPDS criteria [25]. This then allows glycaemic control to vary over time as patients change treatment, and their condition worsens. This constitutes a distinct Markovian sub-model, calibrated with transition rates (Table 2) which generates rates of change consistent with published evidence of therapy changes [34]. During calibration it became clear that the secular rise in $\mathrm{HbA}_{1 \mathrm{c}}$ is largely determined by the rate of transition to insulin therapy, and degree of glycaemic control achievable with insulin. Major hypoglycaemic events are estimated by separate linear functions of $\mathrm{HbA}_{1 \mathrm{c}}$ for each of the four therapy stages derived from UKPDS data in relation to the actual treatment received [25].

Model calibration. Initially, the model was calibrated for the majority white ethnic group, which constitutes $93.5 \%$ of the population of Great Britain [35]. Overall mortality rates are similar to those used in U.S. [21]. However, in the absence of reliable measures of relative mortality risk for morbidity states within each of the microvascular complication modules, the risks were estimated by a variance-minimisation heuristic to reconcile the overall mortality at each age in the mortality module with the implied mortality calculated for each complication module. The results are shown in Table 3 , and are broadly consistent with increasing risk over time as morbidity increases.

Microvascular transition probabilities generally were adjusted to reproduce the main Wisconsin Epidemiologic Study of Diabetic Retinopathy findings on cumulative incidence of morbid states (as referenced by Eastman [21]). Eastman used power functions of $\mathrm{HbA}_{1 \mathrm{c}}$ to represent the influence of glycaemic levels on transition rates. However, we used linear functions with threshold in the normal range of $\mathrm{HbA}_{1 \mathrm{c}}$. Incidence rates for lower extremity PVD from study [36] of $2.13 \%$ per annum for females and $1.76 \%$ per annum for males were used. Transition rates from neuropathy or PVD to chronic ulceration ( $5 \%$ per annum), and to first amputation from chronic ulceration ( $5 \%$ per annum) or PVD ( $2 \%$ per annum), were estimated so as to generate PVD prevalence of about $10 \%$ and a prevalence of diabetic foot ulcer of about $13 \%$, in line with other studies [36].

Health care costs. Previous models of diabetes-related complications have constructed cost estimates by assigning average

Table 2. Annual transition rates for $\mathrm{HbA}_{1 \mathrm{c}}$ module

\begin{tabular}{lllll}
\hline Year $n$ therapy & \multicolumn{3}{l}{ Year $n+1$ therapy } & \\
\cline { 2 - 5 } & Diet and exercise & 1st line OHAs & 2nd line OHAs & Insulin-based \\
\hline Diet and exercise & 0.782 & 0.142 & 0.066 & 0.010 \\
1st line OHAs & 0.059 & 0.882 & 0.051 & 0.008 \\
2nd line OHAs & 0.007 & 0.276 & 0.429 & 0.288 \\
Insulin-based & 0.000 & 0.003 & 0.021 & 0.976 \\
\hline
\end{tabular}


Table 3. Relative risk of death estimated for each complication module (non-diabetics all-causes death rate $=1.0$ )

\begin{tabular}{llrr}
\hline Module & State & Men & Women \\
\hline Nephropathy & None & 1.08 & 1.06 \\
& Microalbuminuria & 1.26 & 2.55 \\
& Gross proteinuria & 1.51 & 3.85 \\
$24.1^{\mathrm{a}}$ & $24.0^{\mathrm{a}}$ & 1.01 \\
Retinopathy & End-stage renal disease & 1.00 & 1.01 \\
& None & 1.00 & 1.69 \\
Background diabetic retinopathy & 1.52 & 8.74 \\
Neuropathy & Macular oedema and/or PDR & 4.98 & 1.00 \\
& Any blindness & 1.00 & 1.00 \\
& None & 1.00 & 1.00 \\
& Neuropathy and/or PVD & 3.50 & 8.64 \\
\hline
\end{tabular}

${ }^{a}$ Averages derived from U.S. end-stage renal disease data

costs to specific diabetes-related events or states generated from an epidemiological model [21, 22]. This 'bottom-up' approach is most appropriate for isolated acute diseases where interactions with other conditions are absent or clearly identifiable and of limited duration. This ensures that the aggregated sum of the average costs of individual disease-related events is likely to yield a reliable approximation to the overall incremental cost attributable to these identifiable events. A multifactorial chronic disease such as diabetes generates specific recognisable conditions and events, but is also known to impact adversely on other apparently unrelated health problems and the resources employed in their treatment [37]. Therefore, it is important to extend the scope of a cost model beyond the direct complications of diabetes to encompass the resources used in treating all diseases. Only in this way can the true impact of diabetes on care costs be reflected, or the incremental effort on costs of alternative treatment scenarios be estimated.

Access to data for a 4-year period (1992-96) from a population database of health care resource use in South Glamorgan, Wales, allowed the development of a costing model based on resource profiles comparing the intensity of resource use between diabetic and non-diabetic populations standardised by age and sex. These profiles covered the whole spectrum of health care services, and were not limited to events or episodes explicitly related to diabetes.

A correlation analysis allowed each resource use profile to be subject to an additive decomposition, and each profile element to be linked to an appropriate model 'driver' variable (e.g. patient numbers in a particular disease state). This approach to cost modelling provides comprehensive estimates of extra costs attributable to a disease, and confirms that incremental costs assignable to a diagnosis of Type II diabetes before complications develop are far greater than can be obtained by analysis of diabetes codes on hospital or other medical records (which generally relate to a small number of extreme cases). An apparent drawback to this approach is that it precludes direct comparison with elements of 'bottom-up' costing from other models, since the incremental costs associated with a cost driver are an aggregation of various effects, some of which can be mutually offsetting.

Results from six cost modules (in patient, out patient, primary care, community health care, diabetes therapy and other medications) were combined to obtain an overall cost estimate for any single year in the remaining lifetime of people newly diagnosed with Type II diabetes. In all cases, an equivalent estimate was generated for age and sex-matched non-diabetic patients, to allow direct comparison of the global impact of Type II diabetes on a whole population.
Data for in patient admissions and bed use were analysed by multiple morbidity categories to assess the potential for costing bias arising where the presence of multiple morbidities might lead to either increased or reduced patient costs compared with the simple addition of single complication costs. Analysis of the incidence of multiple complications showed that single complications are not statistically independent (i.e. patients suffering from one serious complication are more likely also to suffer from other types of complication). However, there was no evidence to suggest that simple addition of treatment costs for individual morbidities is inaccurate, it was concluded that cost adjustments for multiple morbidity are probably unnecessary.

All unit costs within the model can be individually updated by the user, or a single overall inflation factor can be applied to all costs. Equally, some measures of resource use can be adjusted pro-rata to reflect secular changes (e.g. in length of hospital stays). It is anticipated that over time developing clinical practice will modify age and sex resource use profiles, and it will become necessary to recalibrate the cost module.

Hospital inpatient care module. All hospital admissions in a 4year period (1992-96) were assigned by primary diagnosis (International Classification of Diseases-9) to one of nine broad categories (diabetes, nephropathy, retinopathy, neuropathy and skin conditions, heart disease, stroke, neoplasms, cataract and other diseases). In each case, a polynomial or exponential model of the annual admission rate, and the average length of stay by age was fitted by least squares (weighted for case volume) for each sex. Hospital costs were calculated from a fixed cost per admission plus a variable cost per bed-day, the costs being derived from national NHS speciality costs for the dominant specialities for each costing category $[38,39]$. For three groups, the number of affected patients was obtained from the corresponding epidemiological module (nephropathy, retinopathy and neuropathy) with empirical relative weightings of resource intensity between the progression states. Heart disease and stroke costs were linked to the prevalence estimates in the main survival module and other in patient costs were driven directly by surviving patient numbers.

Hospital outpatient care module. A similar approach was followed for outpatient clinic attendances, except that here no direct diagnoses were available for the individual attendances. Instead, analyses were obtained of attendances in the period studied (1995-96), stratified by linked in patient evidence, relating to a prior period of nearly 5 years (1991-96), of patients identified as suffering from one of seven marker conditions 


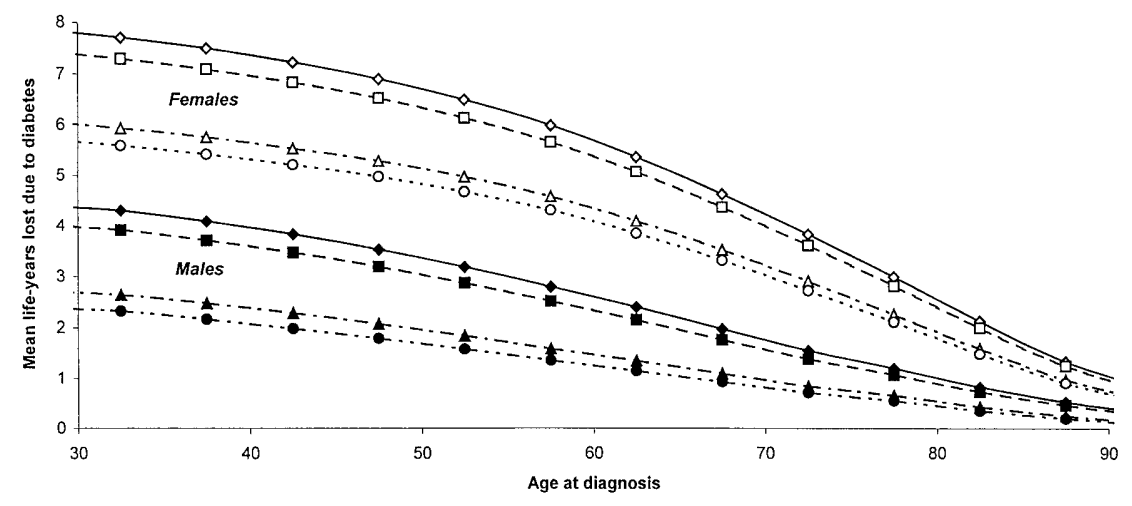

Fig. 2. Mean loss of life due to Type II diabetes by age at diagnosis according to intervention. $\diamond$ UKPDS conventional therapy; $\square$ UKPDS intensive therapy; $\triangle$ UKPDS tight hypertensive control; $\bigcirc$ both UKPDS interventions

(heart disease, stroke, retinopathy, cataract, neuropathy, nephropathy and neoplasms). The incremental influence of each marker condition on outpatient attendance rates was obtained as an age-related regression curve, and the unexplained residue of attendances, obtained after the marker condition models were subtracted, was then related to the overall population. Average NHS speciality-specific clinic visit costs [38,39] were used to estimate aggregate total cost, but these were weighted separately for diabetic and non-diabetic groups to reflect their differing case-mix profiles.

Primary care module. Annual consultation rates at primary care practices reported from the General Practice Morbidity Database Project (GPMDP) in Wales [40] were modelled as age-related curves for each sex and diabetes status combination, applied to the overall surviving population, and costed with Personal Social Services Research Unit, University of Kent, primary care costs [41].

Community health professionals module. Contacts with community-based health professionals (chiropodist, dietician, etc.) were similarly modelled, pro-rata to new referrals from general practitioners in GPMDP [40].

Diabetes therapy module. An average annual therapy cost was calculated for each of the four therapy stages in the glycaemia sub-model, incorporating drug prescriptions costs (according to the selected regimen), dispensing costs, and equipment and consumables for glucose monitoring. These averages were then multiplied by the numbers of patients receiving each type of therapy at any time.

Non-diabetic medications module. Data on prescribed medicines in the Tayside district during 1995 [42] were analysed to yield polynomial age-related models of the number of non-diabetes prescriptions dispensed for each person with and without diabetes. A logistic model was used to estimate the proportion of people with Type II diabetes present. The average cost of each prescription (excluding diabetes therapy) was also estimated for people with and without Type II diabetes separately. These estimates were then combined with patient numbers to provide annual cost estimates for non-diabetes drug use.
Discounting costs and outcomes. The model permits discounting of both costs and benefits at user defined rates. However, the relevance of discounting depends on the perspective of the user and the policy questions addressed. Using the model to exemplify a whole population in steady state permits a care funder to assess the long-term impact on the overall annual care budget and outcomes of adopting a particular policy, and in this case discounting is irrelevant. However, employing the model with selected sub-cohorts yields results equivalent to conventional longitudinal analysis where discounting is appropriate. Results reported below are from the former viewpoint without discounting.

Handling uncertainty. In short-term economic modelling, uncertainty in model assumptions and parameters has traditionally been represented through sensitivity analysis. However, the availability of computing power has permitted development of techniques based on micro-simulation or resampling of data to estimate confidence regions. The appropriateness of such methods to long-term models is questionable on two grounds: the use of simulation involves many assumptions about the source and nature of variations, which could further increase a model's uncertainty, and it is very likely that any confidence regions defined will be so broad that they will offer little information to users. For these reasons we consider that selective sensitivity analysis is the only practicable approach to identifying the sources and relative influence of uncertainty in long-term models. Sensitivity analysis findings are reported below, alongside results illustrating the impact of UKPDS regimens.

\section{Results}

Longevity. Table 4 and Figure 2 show that our model estimates maximum reductions in longevity of 4 years for males and 7 years for females if diabetes is diagnosed between 30 and 34 years of age. The large difference favouring men arises because women with diabetes are at similar cardiovascular mortality risk to men, whereas pre-menopausal non-diabetic women benefit from much lower CVD risks. Simulation of the UKPDS regimens for strict glycaemic control and tight control of blood pressure show that interventions for hypertension are much more beneficial to survival.

Micro-vascular complications. Our model is structured to allow a variety of output formats: cumulative 
Table 4. Estimated reduction in life expectancy due to Type II diabetes mellitus

\begin{tabular}{|c|c|c|c|c|c|c|c|c|}
\hline \multirow{2}{*}{$\begin{array}{l}\text { Age at } \\
\text { diagnosis } \\
\text { of diabetes }\end{array}$} & \multicolumn{4}{|l|}{ Men } & \multicolumn{4}{|l|}{ Women } \\
\hline & $\begin{array}{l}\text { Normal } \\
\text { regimen }\end{array}$ & $\begin{array}{l}\text { Strict } \\
\text { glycaemic } \\
\text { control }\end{array}$ & $\begin{array}{l}\text { Tight blood } \\
\text { pressure } \\
\text { control }\end{array}$ & $\begin{array}{l}\text { Strict } \\
\text { glycaemic } \\
\text { and blood } \\
\text { pressure } \\
\text { control }\end{array}$ & $\begin{array}{l}\text { Normal } \\
\text { regimen }\end{array}$ & $\begin{array}{l}\text { Strict } \\
\text { glycaemic } \\
\text { control }\end{array}$ & $\begin{array}{l}\text { Tight } \\
\text { blood } \\
\text { pressure } \\
\text { control }\end{array}$ & $\begin{array}{l}\text { Strict } \\
\text { glycaemic } \\
\text { and blood } \\
\text { pressure } \\
\text { control }\end{array}$ \\
\hline $30-34$ & 4.1 & $\begin{array}{l}3.8 \\
(3.3-4.1)\end{array}$ & $\begin{array}{l}2.6 \\
(1.8-3.4)\end{array}$ & $\begin{array}{l}2.3 \\
(1.2-3.4)\end{array}$ & 7.3 & $\begin{array}{l}7.0 \\
(6.4-7.4)\end{array}$ & $\begin{array}{l}5.7 \\
(4.8-6.5)\end{array}$ & $\begin{array}{l}5.4 \\
(4.1-6.5)\end{array}$ \\
\hline $40-44$ & 3.7 & $\begin{array}{l}3.4 \\
(2.9-3.7)\end{array}$ & $\begin{array}{l}2.3 \\
(1.5-3.0)\end{array}$ & $\begin{array}{l}2.0 \\
(0.9-3.0)\end{array}$ & 7.0 & $\begin{array}{l}6.6 \\
(6.0-7.0)\end{array}$ & $\begin{array}{l}5.4 \\
(4.5-6.2)\end{array}$ & $\begin{array}{l}5.0 \\
(3.8-6.2)\end{array}$ \\
\hline $45-49$ & 3.4 & $\begin{array}{l}3.1 \\
(2.6-3.4)\end{array}$ & $\begin{array}{l}2.1 \\
(1.3-2.7)\end{array}$ & $\begin{array}{l}1.8 \\
(0.8-2.7)\end{array}$ & 6.7 & $\begin{array}{l}6.3 \\
(5.8-6.7)\end{array}$ & $\begin{array}{l}5.1 \\
(4.3-5.9)\end{array}$ & $\begin{array}{l}4.8 \\
(3.7-5.9)\end{array}$ \\
\hline $50-54$ & 3.1 & $\begin{array}{l}2.8 \\
(2.4-3.1)\end{array}$ & $\begin{array}{l}1.8 \\
(1.1-2.5)\end{array}$ & $\begin{array}{l}1.6 \\
(0.6-2.5)\end{array}$ & 6.3 & $\begin{array}{l}6.0 \\
(5.5-6.3)\end{array}$ & $\begin{array}{l}4.9 \\
(4.1-5.6)\end{array}$ & $\begin{array}{l}4.6 \\
(3.5-5.6)\end{array}$ \\
\hline $60-64$ & 2.4 & $\begin{array}{l}2.1 \\
(1.8-2.4)\end{array}$ & $\begin{array}{l}1.3 \\
(0.8-1.9)\end{array}$ & $\begin{array}{l}1.1 \\
(0.4-1.9)\end{array}$ & 5.3 & $\begin{array}{l}5.0 \\
(4.6-5.3)\end{array}$ & $\begin{array}{l}4.0 \\
(3.4-4.7)\end{array}$ & $\begin{array}{l}3.8 \\
(2.9-4.7)\end{array}$ \\
\hline $65-69$ & 2.0 & $\begin{array}{l}1.8 \\
(1.5-2.0)\end{array}$ & $\begin{array}{l}1.1 \\
(0.6-1.5)\end{array}$ & $\begin{array}{l}0.9 \\
(0.2-1.5)\end{array}$ & 4.6 & $\begin{array}{l}4.3 \\
(3.9-4.6)\end{array}$ & $\begin{array}{l}3.5 \\
(2.9-4.0)\end{array}$ & $\begin{array}{l}3.3 \\
(2.4-4.0)\end{array}$ \\
\hline $70-74$ & 1.5 & $\begin{array}{l}1.4 \\
(1.1-1.5)\end{array}$ & $\begin{array}{l}0.8 \\
(0.4-1.2)\end{array}$ & $\begin{array}{l}0.7 \\
(0.1-1.2)\end{array}$ & 3.8 & $\begin{array}{l}3.6 \\
(3.3-3.8)\end{array}$ & $\begin{array}{l}2.9 \\
(2.4-3.3)\end{array}$ & $\begin{array}{l}2.7 \\
(2.0-3.3)\end{array}$ \\
\hline $75-79$ & 1.2 & $\begin{array}{l}1.1 \\
(0.9-1.2)\end{array}$ & $\begin{array}{l}0.6 \\
(0.3-0.9)\end{array}$ & $\begin{array}{l}0.5 \\
(0.1-0.9)\end{array}$ & 3.0 & $\begin{array}{l}2.8 \\
(2.5-3.0)\end{array}$ & $\begin{array}{l}2.2 \\
(1.8-2.6)\end{array}$ & $\begin{array}{l}2.1 \\
(1.5-2.6)\end{array}$ \\
\hline 80-84 & 0.8 & $\begin{array}{l}0.7 \\
(0.6-0.8)\end{array}$ & $\begin{array}{l}0.4 \\
(0.2-0.6)\end{array}$ & $\begin{array}{l}0.3 \\
(0.0-0.6)\end{array}$ & 2.1 & $\begin{array}{l}2.0 \\
(1.8-2.1)\end{array}$ & $\begin{array}{l}1.6 \\
(1.3-1.9)\end{array}$ & $\begin{array}{l}1.5 \\
(1.1-1.9)\end{array}$ \\
\hline 85-89 & 0.5 & $\begin{array}{l}0.5 \\
(0.4-0.5)\end{array}$ & $\begin{array}{l}0.2 \\
(0.1-0.4)\end{array}$ & $\begin{array}{l}0.2 \\
(0.0-0.4)\end{array}$ & 1.3 & $\begin{array}{l}1.2 \\
(1.1-1.3)\end{array}$ & $\begin{array}{l}1.0 \\
(0.8-1.1)\end{array}$ & $\begin{array}{l}0.9 \\
(0.6-1.1)\end{array}$ \\
\hline
\end{tabular}

Figures in brackets are based on $+/-1$ standard error of the proportional reduction in cardiovascular mortality reported by UKPDS ( $0 \%$ to $-17 \%$ due to intensive glycaemic control and $-15 \%$ to $-43 \%$ due to tight blood pressure control)

incidence, point prevalence and caseload burden of complications by age or duration of diabetes, and these can be generated for individual age or sex incident groups or both, or for a mixed population group. Using a typical age and sex incidence profile for diagnosis of Type II diabetes, Figures 3 and 4 show the cumulative incidence of nephropathy according to the duration of diabetes, and the corresponding point prevalence and estimated current caseload (in a steady-state scenario) for a district generating 1000 new Type II diabetes cases each year. Similar results can be generated for all complications.

Macro-vascular complications. The increased burden due to macro-vascular disease in patients with diabetes is illustrated in Figure 5. The number of patients surviving, and the numbers alive with a history of $\mathrm{CHD}$ and stroke are contrasted with similar figures for a matched incident cohort of people without diabetes.

Multiple morbidity. Patients with Type II diabetes frequently suffer from more than one of the five major complications (CHD, stroke, retinopathy, neuropa- thy and nephropathy). The growing importance of multiple complications with age is revealed in Figure 6 , where over the age of 80 as many patients suffer from more than one serious complication, as suffer from a single morbidity or none.

Glycaemic control progression. The glycaemia submodule accurately reproduces the progression in cohort $\mathrm{HbA}_{1 \mathrm{c}}$ levels reported for UKPDS [25] for both conventional and intensive therapy (Fig. 7).

Health care costs. Use of health care services increases with age for all types of health care and both sexes show broadly similar trends. However, patients with Type II diabetes use health services more frequently than corresponding people matched for age without diabetes. After 40 years of age, patients with Type II diabetes visit their primary care physician 2-3 times more often than other people (Fig. 8A). Patients with Type II diabetes attend hospital specialist clinics about three times a year, whereas other people average less than once per year until they are over 70 years of age (Fig. 8B). For both sexes and at all ages, people with Type II diabetes can expect to re- 

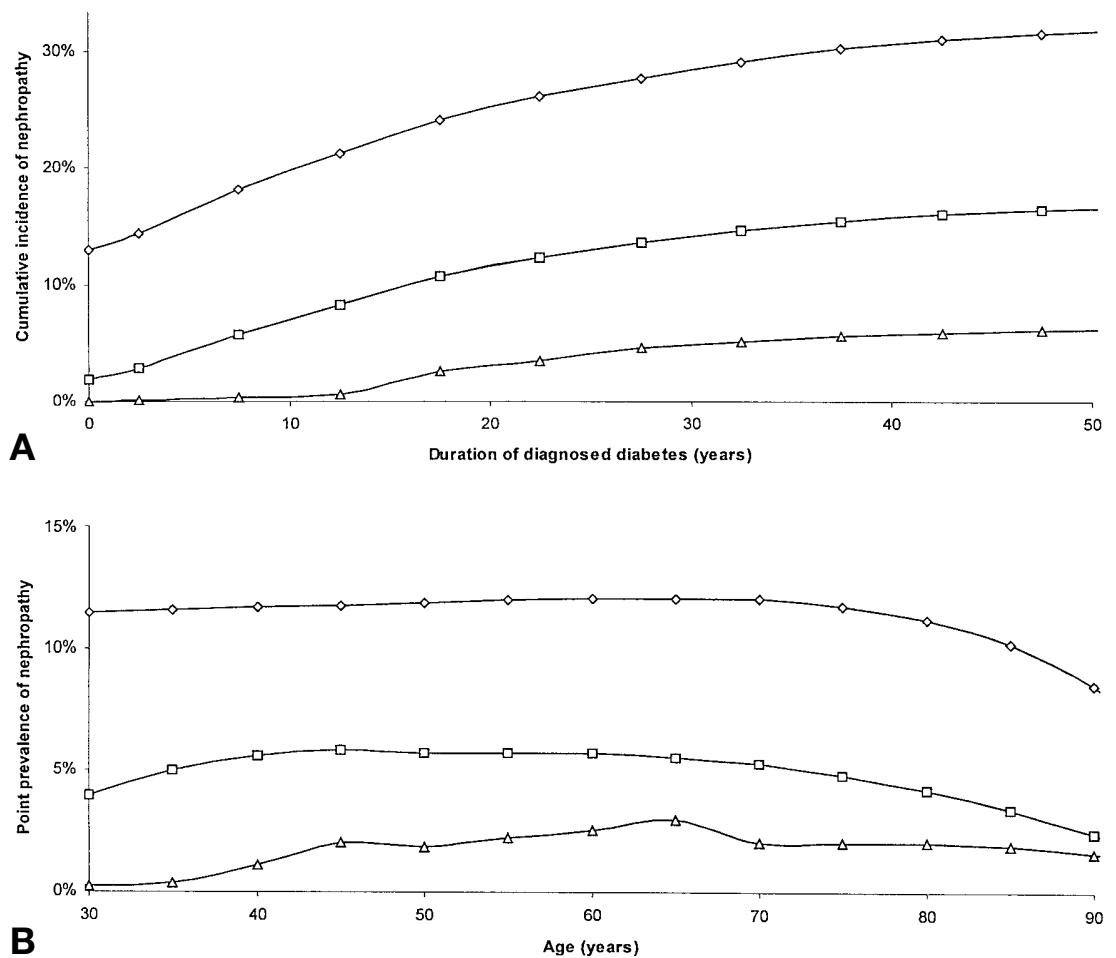

Fig.3. Cumulative incidence of nephropathy in a typical mixed incident cohort by duration of diagnosed diabetes $(\mathbf{A})$ and prevalence of nephropathy in a typical mixed incident cohort by age $(\mathbf{B})$. $\diamond$ microalbuminuria; $\square$ gross proteinuria; $\triangle$ endstage renal disease

quire admission to hospital more frequently than those without diabetes (Fig. 8C), and to stay about 2 days longer in hospital before discharge (Fig. 8D), leading to substantially more intensive use of in patient beds.

Fig.4. Estimated caseload generated by a typical mixed incident cohort (1000 cases per annum) by age, assuming steady state conditions. No nephropathy (light stippling); microalbuminuria (horizontal shading); gross proteinuria (heavy stippling); end-stage renal disease (solid)
These differences in health-care resource use translate into substantial differences in costs. The average man diagnosed with Type II diabetes will incur up to $£ 33000$ in subsequent health care costs compared with up to $£ 15000$ for a man who is without diabetes (ratio of 2.4:1); for a woman the figures are up to $£ 43000$ and up to $£ 22000$ respectively (ratio 1.9:1). The relative difference is particularly large before the age of 60 (cost ratios generally greater than 4:1; Fig.9) because the health services are not often used before this age.

The model generates cost estimates for the remainder of patients' lives from the time Type II diabetes is diagnosed. Table 5 summarises overall health costs expected for a typical 1000 patient annual incident cohort at 1996 UK prices. Because these estimates cover all health costs (including non-diabetesrelated conditions), and also take account of differences in life expectancy, they should be interpreted

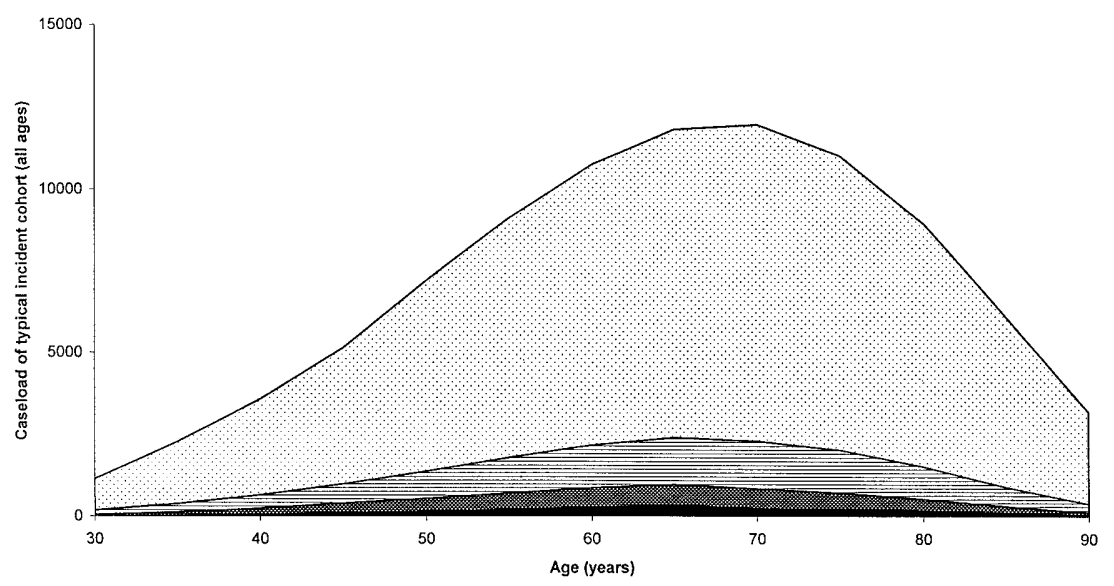




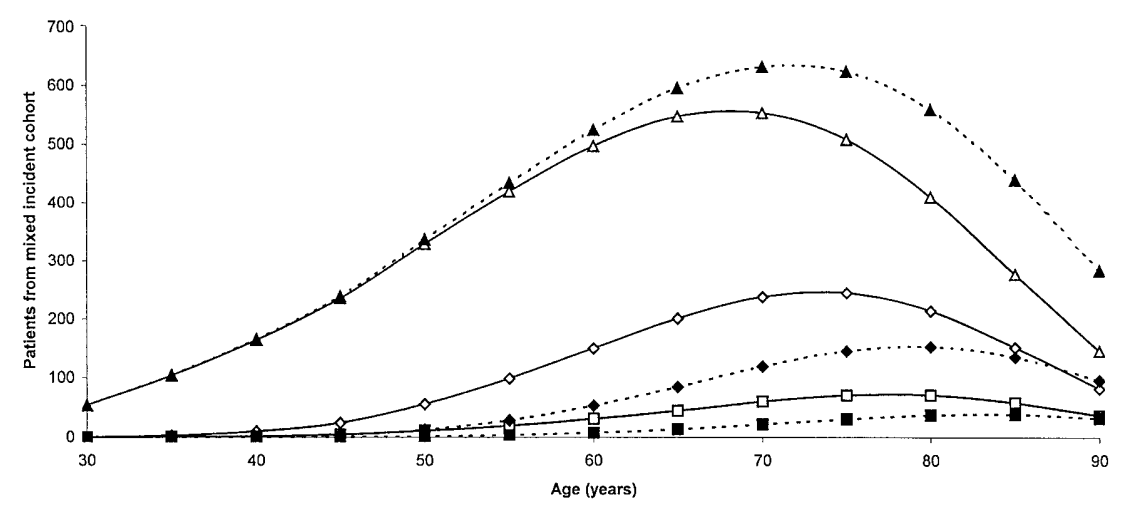

Fig.5. Prevalence of coronary heart disease and history of stroke among patients with diabetes $(-)$ and matched patients without diabetes (--), in a typical mixed incident cohort of 1000 newly-diagnosed patients. $\triangle$ patients alive at specified age; $\diamond$ patients alive with coronary heart disease; $\square$ patients alive with history of stroke

with care. People with diabetes have $102 \%$ greater net lifetime health care costs compared with people without diabetes.

Scenarios based on UKPDS regimens for intensive glycaemic control and tight control of blood pressure are shown in Table 5, using annual additional treatment costs associated with the interventions quoted in the UKPDS economic evaluations [43,44]. These suggest net increases in health costs of $5.2 \%$ and $19.4 \%$ respectively which can be compared with increases in survival of 278 years and 1186 years per 1000 patients, respectively. Although cost and outcome ratios are presented, these cannot be interpreted as conventional incremental cost-effectiveness ra-

Fig. 6. Proportion of patients with diabetes with multiple diabetes-related complications (coronary heart disease, stroke, retinopathy, neuropathy or nephropathy), by age. $\diamond$ No serious diabetes-related complications; $\square$ single serious diabetesrelated complication; $\triangle$ two or more serious diabetes-related complications tios because they include important second-order effects. However, it is important for health policymakers to be aware of the full budgetary consequences of clinical interventions including the net cost to health service providers of care associated with other conditions suffered in later life when life expectancy is extended. Notwithstanding these caveats, the net cost and outcome ratio of both UKPDS regimens is encouraging, (within the range of $£ 6400-£ 7300$ for each additional life year) when compared to new therapies approved for treating other diseases. Figures are also presented in Tables 4 and 5 from a sensitivity analysis based on one standard error either side of the mortality reduction estimates derived from UKPDS findings.

Expected lifetime health care costs (Fig.10) vary according to the age of patients at diagnosis from a mean of up to $£ 70000$ for women diagnosed at age 30 to up to $£ 20000$ for the very oldest patients. At most ages of diagnosis the expected cost of care is more than doubled by the presence of diagnosed diabetes. In general, women incur higher costs than men due to obstetric care for the under 45 year olds and also due to their greater life expectancy.

In a steady-state environment, we can estimate the annual costs of diabetes care in a population from the expected lifetime costs across a typical incident cohort (1000 new cases for each). Figure 11 shows that the greatest costs for women with diabetes are in-

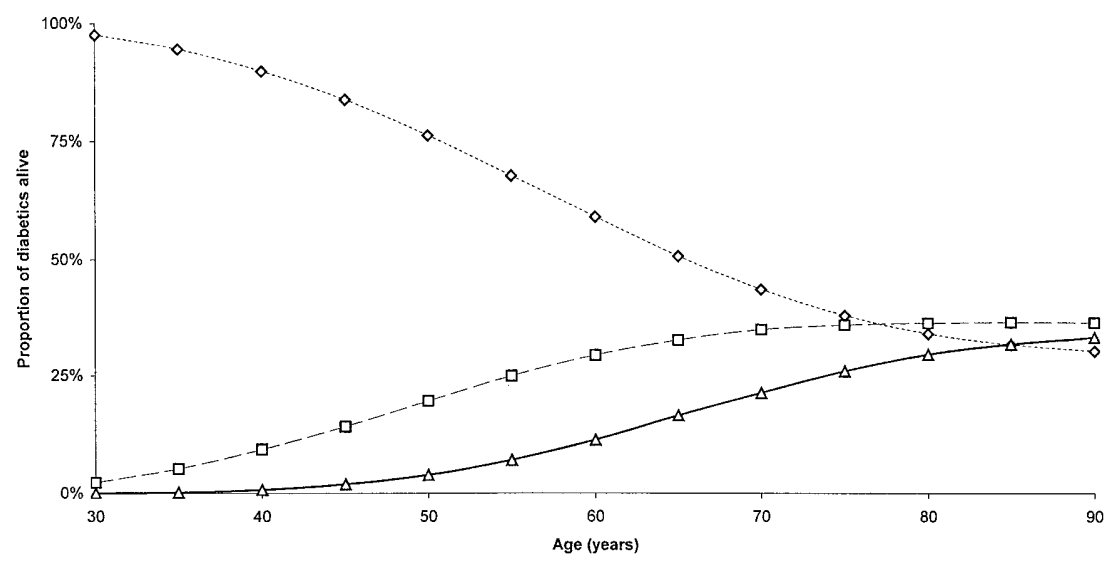




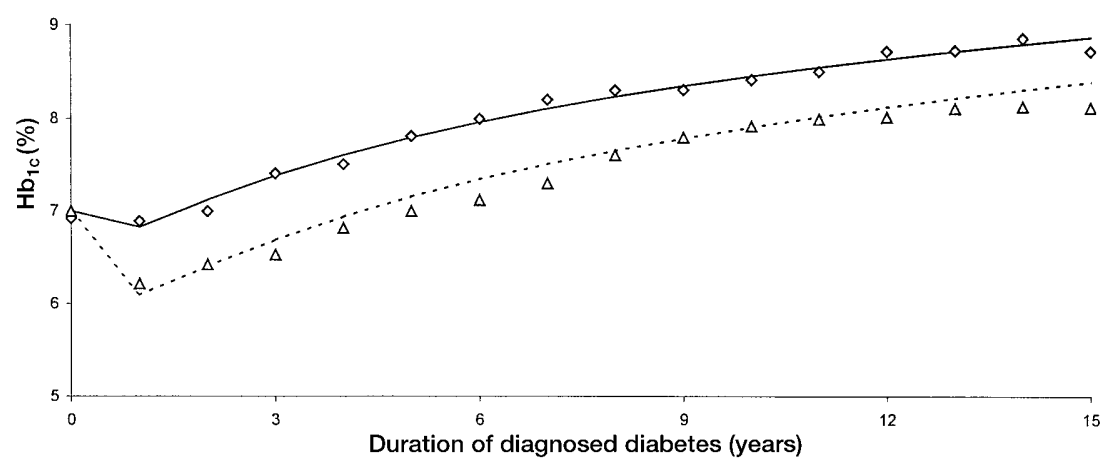

Fig.7. Model estimates of progression in $\mathrm{HbA}_{1 \mathrm{c}}$ compared with UKPDS observations. $\diamond$ Median $\mathrm{HbA}_{1 \mathrm{c}}$ for UKPDS conventional therapy; $\triangle$ median $\mathrm{HbA}_{1 \mathrm{c}}$ for UKPDS intensive therapy; model estimate of mean $\mathrm{HbA}_{1 \mathrm{c}}$ for conventional therapy $(-)$; model estimate of mean $\mathrm{HbA}_{1 \mathrm{c}}$ for intensive therapy $(--)$

curred at the ages of $80-84,10$ years later than for men. At all ages the cost of treating people with diabetes exceeds that estimated for other patients, though for the very elderly the survival advantage of the absence of diabetes effectively eliminates the difference in cost.

\section{Discussion}

Type II diabetes is an insidious chronic condition that requires long-term treatment and is associated with increasing morbidity and mortality as the disease progresses [1]. Early and continued efforts to maintain glycaemic control and to treat hypertension reduce the incidence of complications associated with Type II diabetes [25, 31].

The model described in this study provides decisionmakers with information about the impact of Type II diabetes within a cohort by direct comparison of equivalent groups of patients with and without Type II diabetes. It also provides a vehicle for assessing the long-term economic benefits, in terms of direct costs and the required health care resources, of

Table 5. Lifetime health costs for typical incidence cohort (1000 patients) from time of diagnosis (£ $000 \mathrm{~s}$ at 1996 prices)

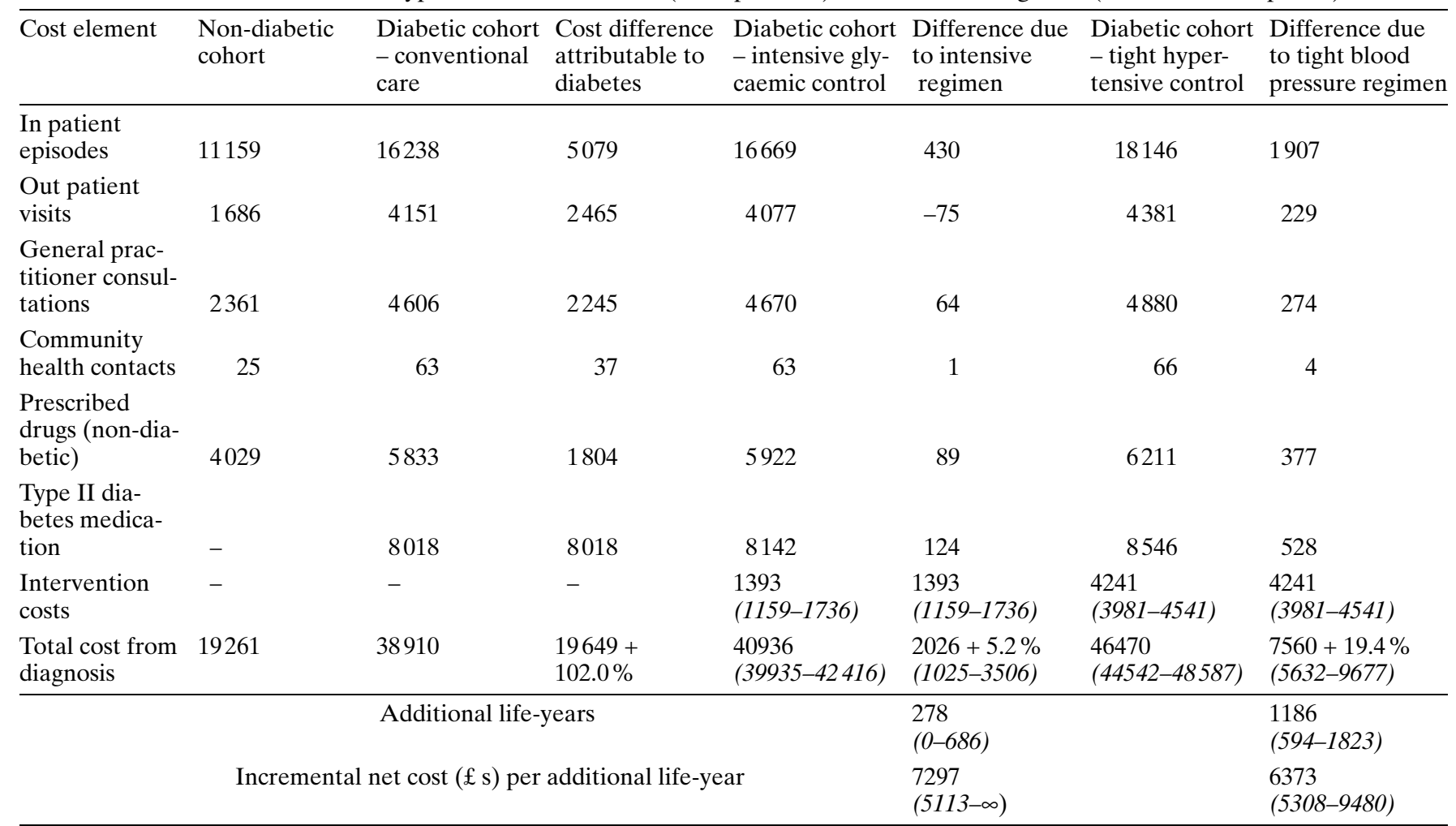

Figures in brackets are based on $+/-1$ standard error of the proportional reduction in Cardio-vascular mortality reported by UKPDS ( $0 \%$ to $-17 \%$ due to intensive glycaemic control, and $-15 \%$ to $-43 \%$ due to tight blood pressure control) 
A. Bagust et al.: Long-term economic model of Type II diabetes
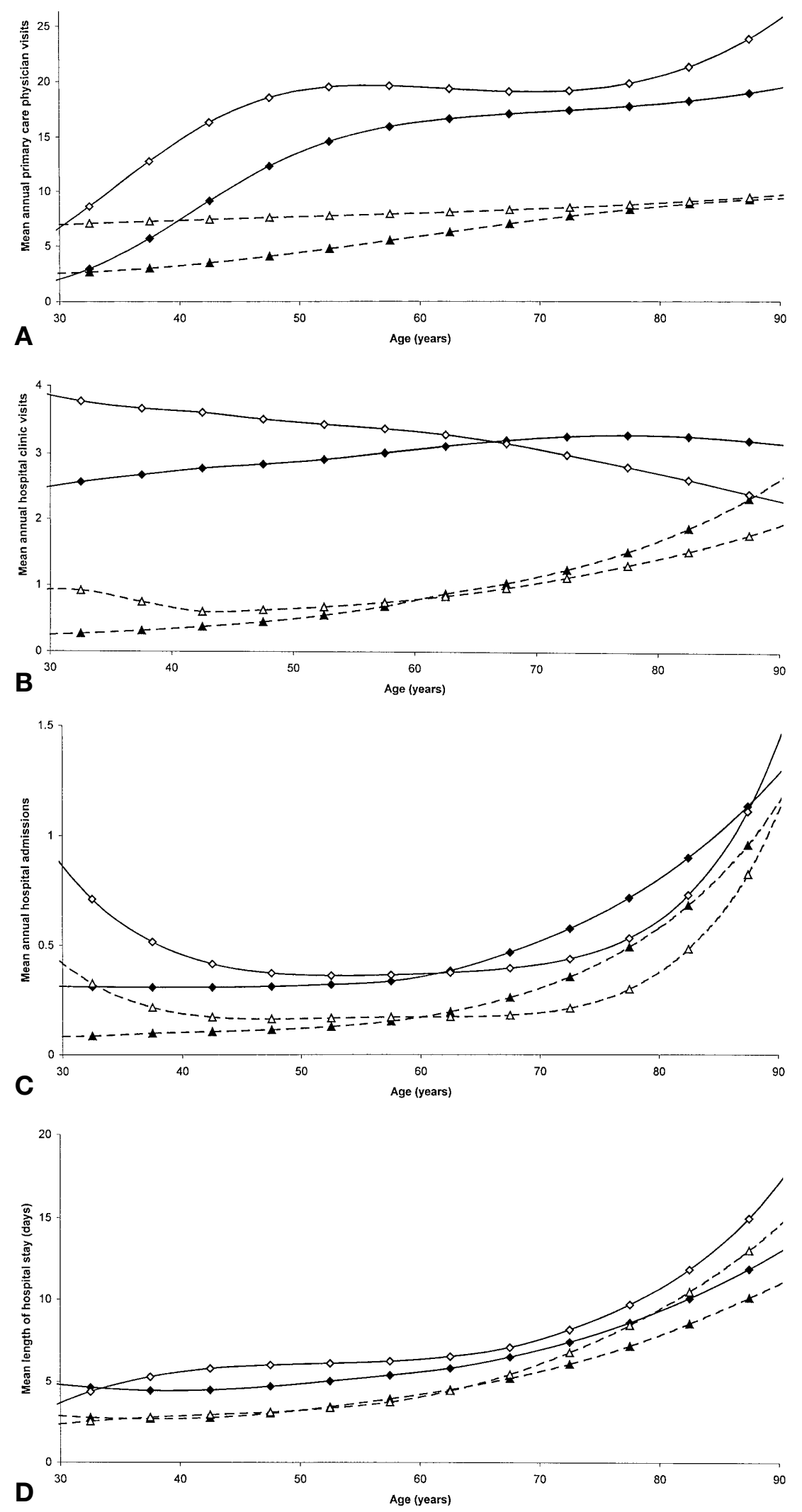

Fig. 8. Mean annual A primary care physician visits; B hospital specialist clinic visits; $\mathbf{C}$ hospital admissions; D and mean length of stay for hospital in patient admissions by age, sex and diabetic status. $\diamond$ Type II diabetes; $\triangle$ no Type II diabetes; men (-); women (---) 


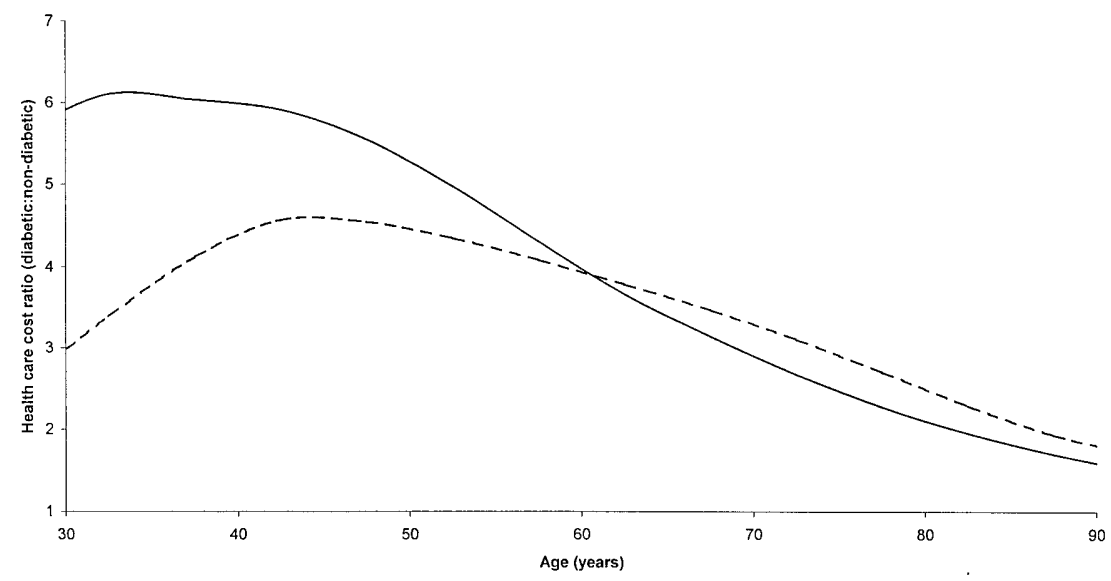

Fig.9. Mean ratio of total health care costs for persons with diabetes versus those without diabetes by age and sex. men (-); women (-- )

existing and new treatment regimens for Type II diabetes, as well as a range of public health policy initiatives. The model was extensively redesigned and developed from the original US (NIH) model [21, 22], for use initially in the UK.

The long-term modelling of a chronic multi-factorial disease such as diabetes involves a large number of assumptions to be made which extrapolate beyond the existing evidence base. It is important that such assumptions are critically examined, as they affect model parameters, functional relationships between model variables, and indeed the essential structure of the model. In particular the accurate representation of mortality and survival is crucial to the realistic estimation of the extent of lifetime morbidity experi-

Fig. 10. Expected health costs from diagnosis of diabetes to death by age at diagnosis. $\diamond$ men; $\square$ women; Type II diabetes $(-)$; no Type II diabetes (---) enced, and consequently to the costing of healthcare interventions.

A number of important revisions were made to the original NIH model, regarding the relationships between the mortality, nephropathy, neuropathy and retinopathy modules, based on a detailed examination of the current epidemiological literature. Apart from recasting the NIH model to avoid reliance on random number generation, the most important changes made in the development and adaptation for the UK context, are in the mortality module and its relationship to the other elements of the model. In the NIH model, mortality was introduced using the nephropathy module. However, we have found no evidence to support this structural asymmetry in favour of any one complication. In light of this, all relationships within the model have been reviewed and mortality has been placed at the core of the model, with the remaining three complication modules defining the distribution of surviving patients.

While the NIH model estimated a loss of life expectancy of 10 years for a middle-aged patient, newly diagnosed with diabetes, the current model placed this value at 3 years for men and 7 years for women. This suggests that Eastman and co-workers [21,22] could have underestimated the life expectancy of people with Type II diabetes (and therefore the dura-

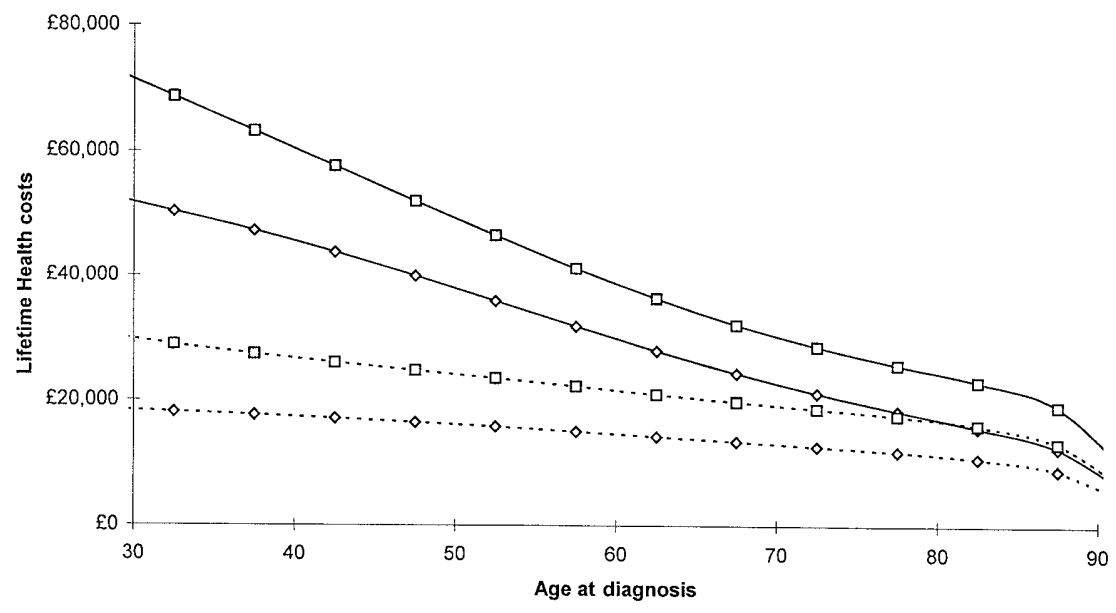




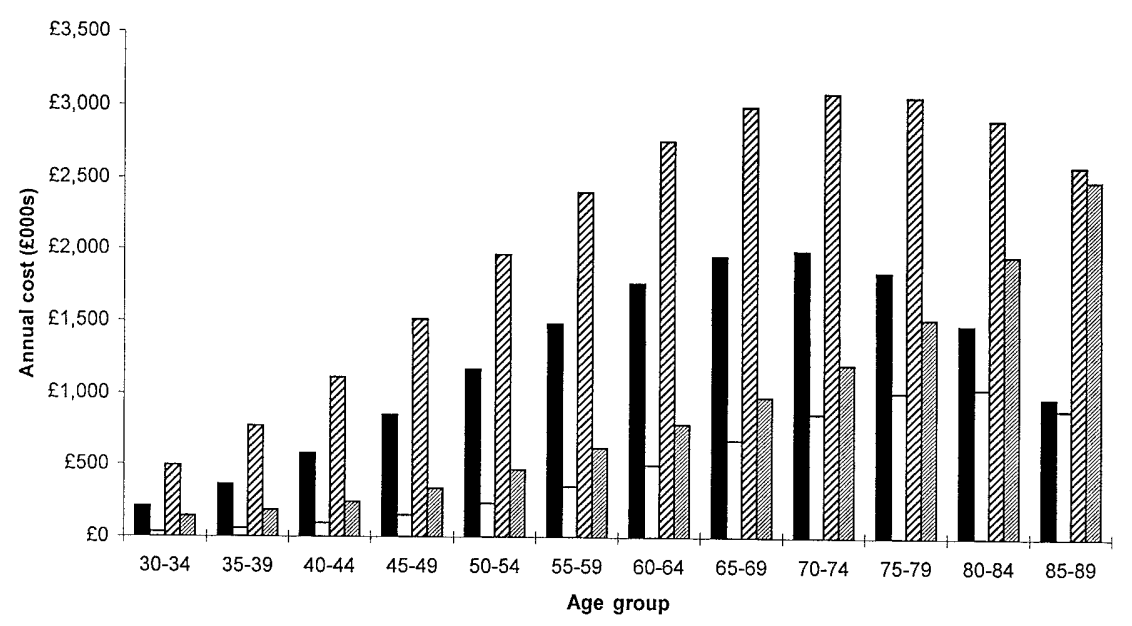

Fig. 11. Estimated annual health care costs by age, sex and diabetes status generated by incidence of 1000 cases per annum, assuming steady state conditions. $\square$ men with Type II diabetes; $\square$ men without Type II diabetes; women with Type II diabetes (ऑ); women without Type II diabetes (ॠ)

tion of their morbidity), but overestimated the proportion of remaining life spent in the more severe morbid states. This illustrates that results from such complex models are often more influenced by assumptions about the natural history and course of the disease, reflected in the model structure, than by simple uncertainty about specific parameter values (the usual basis for sensitivity analyses).

Changes have also been made to the content of the complications modules including redefinition of the morbid states of the neuropathy and retinopathy modules, to account for more recent clinical data. Epidemiological and resource use observational data from the South Glamorgan diabetes database has allowed the incorporation of multiple morbidity patterns and a greatly enhanced costing module.

The current mortality module employs risk equations based on the Framingham study. As these do not include any measure of hyperglycaemia, the main model does not yet include a direct mechanism for using glycaemia levels to influence mortality rates. However, the principal survival and macrovascular benefits reported by the UKPDS are incorporated by risk modification factors and provide a good approximation to reported outcomes. The model can easily be adapted to accommodate the necessary additional factors required to moderate mortality estimates in relation to glycaemic control and other factors such as dyslipidaemia.

The new model structure is designed to generate cost and outcome estimates from several perspectives, allowing clinicians and epidemiologists to explore the implications of clinical trial results on the same basis as health service planners and payers, whose interest is in budgetary impact including the full long-term effects of changes in life expectancy on other (non-diabetic) health costs. Economic evaluations of clinical trials do not normally take account of such second-order effects, so that published costeffectiveness results cannot be readily translated into cost consequences for service planning. This is demonstrated by the example of UKPDS where the model generates incremental cost and outcome ratios less favourable than those previously reported [43, 44].

Although the model permits use of utility measures as modifiers to duration of life (i.e. to obtain Quality-Adjusted Life Years - QALYs), a consistent set of utility values has only recently become available from the CODE-2 study [45]. Incorporation of these data into our model has demonstrated that the impact of multiple complications on patient outcomes (as measured in QALYs) is comparable to that suffered by people with Type II diabetes due to reduced life expectancy [46].

A recent direct comparison of two diabetes models [47] has highlighted the difficulties involved in validation of such models. Models apparently drawing on the same or similar evidence bases yielded very different results for both outcomes and costs, serving to emphasise how long-term models tend to propagate and amplify differences. Because large studies do not address the detailed questions faced in model construction, it is not normally possible to verify a model against independent data which has not earlier been used to calibrate the model or define its structures. Direct comparison of models and extensive sensitivity analysis helps to identify those features on which further research or methodological development is required to improve future models. In this respect there is no 'gold standard' for diabetes modelling: there is only a process of iterative evolution in which the major sources of conflict between results from different models are identified, new evidence sought, and then further comparisons made. 
Acknowledgements. This study was supported by a research grant from Glaxo Wellcome Research and Development. We would like to thank David Harrison for his editorial assistance during preparation of the manuscript.

\section{Appendix 1}

Five-year combined transition rates for nephropathy

The four nephropathic states are designated $S_{i}, \mathrm{i}=1$ to 4 . For each state we define:

1. The annual progression rate to the next state $S_{i}+1$ as $T_{i}, \mathrm{i}=1$ to 4 , where $T_{4} \equiv 0$

2. The annual death rate in state $S_{i}$ as $D_{i}, \mathrm{i}=1$ to 4

3 . The annual residue of patients remaining in state $S_{i}$ after deaths and progressions as $\omega_{\mathrm{i}}=1-\mathrm{T}_{\mathrm{i}}-\mathrm{D}_{\mathrm{i}}, \mathrm{i}=1$ to 4

We define a compound residue function $\boldsymbol{\Re}$ as follows:

$$
\begin{gathered}
\mathfrak{R}(1: a, b, c, d, e)=\sum\left(\omega_{a}{ }^{i} \cdot \omega_{b}{ }^{j} \cdot \omega_{c}{ }^{k} \cdot \omega_{d}{ }^{l} \cdot \omega_{e}{ }^{m}\right) \\
i+j+k+1+m=1 \\
\equiv \omega_{a}+\omega_{b}+\omega_{c}+\omega_{d}+\omega_{e}
\end{gathered}
$$

And so on to ...

$\Re(5: a)$

$$
=\sum_{i=5}\left(\omega_{a}^{i}\right) \equiv \omega_{a}^{5}
$$

Then for a unit case in state $S_{i}$ at time $t=0$, the expected occupancy of state $S_{j}$ at $t=5$ years is given by

$S_{j}=\mathfrak{\Re}(5+i-j: i, i+1, \ldots, j) . \prod_{f=i}^{4} T_{f} / \prod_{g=j}^{4} T_{g}, j=i$ to 4

In the initial 5-year period of a cohort, patients have an equal probability of commencing in any of 5 separate years, so the transition rates in this period are given as the average of 1-, 2-, 3-, 4- and 5-year combined transition rates. Expected deaths are equivalent to the probability residue of all living states.

\section{Appendix 2}

\section{Summary of model characteristics}

Model type. Deterministic Markov model, with subsidiary modules reconciled to central survival module. Annual transitions compresses algebraically into 5 -year steps. Thirty parallel sub-cohort models by sex and 5-year bands of age-at-diagnosis, calculated simultaneously. Each element of the model is paralleled by an equivalent non-diabetic model.
Complications. CHD and Stroke estimated as substates of survival estimates. Three independent microvascular sub-models, reconciled to survival totals. Prevalence of multiple complications estimated from frequency distributions in South Glamorgan database[37].

Mortality. CVD mortality based on Framingham equations [48]. Other mortality derived from OPCS mortality statistics for UK [49]. Competing risks model to combine mortality elements.

$C V D$. Framingham equations[48] for 1st MI, 1st Stroke, and CVD-related deaths used to estimate prevalence of CHD and Stroke in surviving cohorts.

Retinopathy and macular oedema. Redesigned submodel with nine distinct states representing combinations of possible conditions and severities. Default transition rates from linear function of $\mathrm{HbA}_{1 \mathrm{c}}$ (based on WESDR results), with option to use Eastman rates.

Nephropathy. Sub-model with four states (as Eastman). Default transition rates from linear function of $\mathrm{HbA}_{1 \mathrm{c}}$ (based on WESDR results), with option to use Eastman rates.

Neuropathy, PVD and lower extremity amputation. Redesigned integrated model with seven distinct states based on Boulton's algorithm. [33] Default transition rates from linear function of $\mathrm{HbA}_{1 \mathrm{c}}$ (based on WESDR results), with option to use Eastman rates.

$H b A_{1 c}$. Independent model of annual transitions between four therapy modes, with transition rates inferred from Hayward [34].

Costs. Resource use age-sex profiles derived from South Glamorgan database [37] and GPMDP[40] for both Type II diabetics and non-diabetics, and linked to complication state drivers. General health spending not specifically linked to complications also profiled and included. Unit costs from UK national sources $[38,39,41]$.

\section{References}

1. McCarty D, Zimmet P (1994) Diabetes 1994 to 2010: Global estimates and projections. International Diabetes Institute, Melbourne

2. Amos AF, McCarty DJ, Zimmet P. (1997) The Rising Global Burden of Diabetes and its complications: Estimates and projections to Year 2010. Diabetic Medicine 14: s7-s85

3. Harris MI, Hadden WC, Knowler WC et al. (1987) Prevalence of diabetes and impaired glucose tolerance and plasma glucose levels in US population aged 20-74 yr. Diabetes 36: 523-534 
4. Harris MI, Klein R, Welborn TA, Kniuman MW (1992) Onset of NIDDM occurs at least 4-7 years before clinical diagnosis. Diabetes Care 15: 815-819

5. Glasgow RE, Ruggiero L, Eakin EG et al. (1997) Quality of life and associated characteristics in a large national sample of adults with diabetes. Diabetes Care 20: 562-567

6. Alberti KG (1997) The costs of non-insulin-dependent diabetes mellitus. Diabetic Medicine 14: 7-9

7. Humphrey LL, Ballard DJ, Frohnert PP et al. (1989) Chronic renal failure in non-insulin-dependent diabetes mellitus: a population-based study in Rochester, Minnesota. Ann Intern Med 111: 788-796

8. Klein R (1995) Hyperglycaemia and microvascular and macrovascular disease in diabetes. Diabetes Care 18: 258-268

9. Hadden DR, Patterson CC, Atkinson AB et al. (1997) Macrovascular disease and hyperglycaemia: 10-year survival analysis in Type II diabetes mellitus: the Belfast diet study. Diabet Med 14: 663-672

10. The Diabetes Control and Complications Trial Research Group (1993) The effect of intensive treatment of diabetes on the development and progression of long-term complications in insulin-dependent diabetes mellitus. N Engl J Med 329: 977-986

11. Ohkubo Y, Kishikawa H, Araki E et al (1995) Intensive insulin therapy prevents the progression of diabetic microvascular complications in Japanese patients with noninsulin-dependent mellitus: a randomized prospective 6year study. Diabetes Res Clin Pract 28: 103-117

12. Moss SE, Klein R, Klein BE et al. (1994) The association of glycemia and cause-specific mortality in a diabetic population. Arch Intern Med 154: 2473-2479

13. Donahue RP, Orchard TJ (1992) Diabetes mellitus and macrovascular complications. An epidemiological perspective. Diabetes Care 15: 1141-1155

14. Gall MA, Borch-Johnsen K, Hougaard P et al. (1995) Albuminuria and poor glycemic control predict mortality in NIDDM. Diabetes 44: 1303-1309

15. Donahue RP (1994) The insulin resistance syndrome (syndrome X) and risk factors for coronary heart disease. Endocrinology 4: 112-116

16. Nathan DM, Meigs J, Singer DE (1997) The epidemiology of cardiovascular disease in type 2 diabetes mellitus: how sweet it is ... or is it? Lancet 350: S4-S9

17. Lillioja S, Mott DM, Howard BV et al. (1988) Impaired glucose tolerance as a disorder of insulin action. Longitudinal and cross-sectional studies in Pima Indians. N Engl J Med 318: 1217-1255

18. Keen H, Jarrett RJ, McCartney P (1982) The ten-year follow-up of the Bedford survey (1962-1972): glucose tolerance and diabetes. Diabetologia 22: 73-78

19. Groop LC, Widen E, Ferrannini E (1992) Insulin resistance and insulin deficiency in the pathogenesis of Type II (noninsulin-dependent) diabetes mellitus: errors of metabolism or of methods? Diabetologia 36: 1326-1331

20. Unger RH, Grundy S (1985) Hyperglycaemia as an inducer as well as a consequence of impaired islet cell function and insulin resistance: implications for the management of diabetes. Diabetologia 28: 119-121

21. Eastman RC, Javitt JC, Herman WH et al. (1997) Model of complications of NIDDM. I. Model construction and assumptions. Diabetes Care 20: 725-734

22. Eastman RC, Javitt JC, Herman WH et al. (1997) Model of complications of NIDDM. II. Analysis of the health benefits and cost-effectiveness of treating NIDDM with the goal of normoglycaemia. Diabetes Care 20: 735-744
23. Palmer AJ, Brandt A, Gozzoli V, Weiss C, Stock H, Wenzel $\mathrm{H}$ (2000) Outline of a diabetes disease management model: principles and applications. Diabetes Res Clin Prac 50 [Suppl 3]: S47-S56

24. Brown JB, Russell A, Chan W, Pedula K, Aickin M (2000) The global diabetes model: user friendly version 3.0. Diabet Res Clin Prac 50 (Suppl 3): S15-S46

25. UK Prospective Diabetes Study Group (1998) Intensive blood-glucose control with sulphonylureas or insulin compared with conventional treatment and risk of complications in patients with type 2 diabetes (UKPDS 33). Lancet 352: $837-853$

26. UK Prospective Diabetes Study Group (1998) Tight blood pressure control and risk of macrovascular and microvascular complications in type 2 diabetes: UKPDS 38. BMJ 317: 703-712

27. Morgan CL, Currie CJ, Stott NC, Smitheres M, Butler CC, Peters JR (2000) The prevalence of multiple diabetes-related complications. Diabet Med 17: 146-151

28. Geiss LS, Herman WH, Smith PJ (1995) Mortality in NonInsulin-Dependent Diabetes In: Harris MI, Cowie CC, Stern MP, Boyko EJ, Reiber GE, Bennet PH (eds) Diabetes in America, $2^{\text {nd }}$ Edn, National Institutes of Health, Bethesda

29. Lowe LP, Kiang Liu, Greenland P et al. (1997) Diabetes asymptomatic hyperglycaemia and 22-year mortality in black and white men. Diabetes Care 20: 163-169

30. Javitt JC, Aiello LP, Bassi LJ et al. (1991) Detecting and treating retinopathy in patients with type 1 diabetes mellitus. Ophthalmology 10: 1565-1573

31. Mogensen CE, Schmitz A, Damsgaard EM (1990) Microalbuminuria a predictor of proteinuria and early mortality in NIDDM. Diabetes Nutr Metab 3 [Suppl 1]: 77-86

32. UK Prospective Diabetes Study Group (1991) UKPDS VIII: Study design, progress and performance. Diabetologia 34: 877-890

33. Boulton AJM (1997) Late Sequelae of Diabetic Neuropathy In: Boulton AJM (ed.) Diabetic Neuropathy Marius Press, Carnforth, UK pp63-76

34. Hayward RA, Manning WG, Kaplan SH et al (1997) Starting insulin therapy in type 2 diabetes: effectiveness, complications and resource utilization JAMA 278: 1663-1669

35. Matheson J, Summerfield C (eds) for Office of National Statistics. Population by ethnic group and age, 1998-99 in Social Trends 30: 2000 edition. The Stationery Office, London

36. Palumbo PJ, Melton LJ (1995) In: Harris MI, Cowie CC, Stern MP, Boyko EJ, Reiber GE, Bennet PH (eds) Diabetes in America, 2nd edn, National Institutes of Health, Bethesda

37. Currie CJ, Morgan CL, Peters JR (1998) The epidemiology and cost of inpatient care for peripheral vascular disease, infection, neuropathy and ulceration in diabetes. Diabetes Care 21: 42-48

38. NHS Executive (1997) English Trust Financial Returns (1996/97) Department of Health, London

39. NHS Executive (1998) The New NHS-Reference Costs 1998, Department of Health, London

40. Morgan CL, Currie CJ, Hunt J et al. (2000) Relative activity and referral patterns for diabetes and non-diabetes in general practice. Diabet Med 17: 230-235

41. Netter A, Dennett J (1997) Unit costs of health and social care, Personal Social Services Research Unit, University of Kent, Canterbury

42. Evans JMM, MacDonald TM, Leese GP, Rua DA, Morris AD (2000) Impact of Type 1 and Type 2 diabetes on pat- 
terns and costs of drug prescribing. Diabetes Care 23: 770-774

43. UK Prospective Diabetes Study Group (1998) Cost effectiveness analysis of improved blood pressure control in hypertensive patients with type 2 diabetes: UKPDS 40. BMJ 317: 720-726

44. UK Prospective Diabetes Study Group (2000) Cost effectiveness of an intensive blood glucose control policy in patients with type 2 diabetes: economic analysis alongside randomised controlled trial (UKPDS 41). BMJ 320: 1373-1378

45. Mera RM, Bakst AW, Auland M (2001) Independent predictors of Quality of Life in Type 2 Diabetes: The CODE2 Experience. Diabetes 50 [Suppl 2]: A77 (Abstract)
46. Bagust A, Hopkinson PK, Mera RM, Bakst AW, Currie CJ (2001) Type 2 diabetes impact on quality-adjusted life expectancy. Diabetologia 44 (Suppl. 1): A253

47. Brown JB, Palmer AJ, Bisgaard P, Chan W, Pedula K, Russell A (2000) The Mt.Hood challenge: cross-testing two diabetes simulation models. Diabetes Res Clin Pract 50 [Suppl 3]: S57-S64

48. Anderson KM, Odell PM, Wilson PW et al. (1991) Cardiovascular disease risk profiles. Am Heart J 12: 293-298

49. Office for National Statistics (1996) Mortality statistics: cause: review of the Registrar-General on deaths by cause, sex and age in England and Wales, 1995. The Stationery Office, London 